\title{
ДЕЯТЕЛЬНОСТЬ ТНК С ГОСУДАРСТВЕННЫМ УЧАСТИЕМ НА СОВРЕМЕННОМ ЭТАПЕ
}

\author{
(c) 2019 Ольга Крецу \\ аспирантка 3 года обучения при кафедре Международных экономических отношений \\ и внешнеэкономических связей (МЭО и ВЭС) им. Н.Н. Ливенцева \\ Московский государственный институт международных отношений \\ МГИМО МИД России, Россия, Москва \\ E-mail: olga-cretu92@mail.ru
}

Проанализированы особенности деятельности ТНК с государственным участием, начиная с 2011 года, когда ЮНКТАД посвятила данной теме целый раздел в ежегодном Отчете о мировых инвестициях. Данный вид ТНК являются новым феноменом, поэтому методология исследования объекта еще не до конца разработана, активно ведется сбор данных. В статье представлены тенденции в их стратегиях и роль государства в их развитии.

Ключевые слова: транснациональные корпорации, ТНК, ТНК с государственным участием, интернационализация, глобализация.

Отношения между экономическими субъектами и государством всегда представляли особый интерес для экономистов. Изучение этих взаимоотношений особенно актуально в наши дни, когда мир погружен в процессах глобализации и, кажется, что уже стерты все границы, ведь факторы производства свободно передвигаются. Особенно ярко подтверждают это транснациональные корпорации (ТНК), которые проводят глобальные стратегии развития.

Однако государство продолжает оставаться чуть ли не единственным суверенным субъектом системы международных экономических отношений (МЭО), ведь оно имеет право проводить независимую экономическую политику, не смотря на множество интеграционных объединений, в которых может состоять. Государство может выразить свою независимость и повлиять на деятельность ТНК несколькими путями, о которых далее пойдет речь.

Теоретической и методологической основой данного исследования послужили статьи зарубежных ученых по проблематике ТНК в мировой экономике. В процессе работы применялись следующие методы экономического анализа: сравнение, анализ и синтез, противопоставление. Все расчеты и сравнения, построение таблиц и рисунков осуществлялось на основе базы даннЫХ ЮНКТАД.

Каким же образом государство может повлиять на деятельность ТНК? Одним из интересных явлений последнего времени, отмеченных

ЮНКТАД в World Investment Report (WIR), стало укрепление на мировой арене THK с государственным участием, полностью принадлежащих государству или, в которых государство владеет значительным или контрольным пакетом акций [5]. Следует с самого начала уточнить, что в терминологии ЮНКТАД, контрольным считается пакет акций, составляющий $10 \%$ и более, который предоставляет держателю, в данном случае государству, право вето и возможность повлиять на принятие важных решений в компании.

Несмотря на негативное влияние финансово-экономического кризиса 2008-2009 гг., государственные ТНК продолжают играть важную роль в мировой экономике. ЮНКТАД выявила в 2010 г. около 650 ТНК с государственным участием с более 8500 иностранными филиалами [5], а в 2019 г. - более чем в два раза больше таких компаний, а именно 1500 ТНК с более 86 тыс. иностранными филиалами по всему миру [7]. В 2017 г. доля государственных ТНК составила около 1,5\% всех ТНК в мире, а их филиалы $-10 \%$ от всех филиалов всех ТНК мира [6]. Конечно, количество ТНК с государственным участием невелико, но 16 из 100 крупнейших нефинансовых и 41 из 100 ТНК из развивающихся стран и стран с переходной экономикой принадлежат государству $[6,7]$.

Почему же меньше чем за 10 лет наблюдений количество ТНК с государственным участием в мире увеличилось почти в два раза, а количество 
зарубежных филиалов - аж в 10 раз?! Важно отметить с самого начала, что данный тип ТНК изучается относительно недавно и методика соотнесения ТНК к государственному типу еще не до конца разработана и все еще совершенствуется.

Согласно статьям одного из ключевых исследователей ТНК с государственным участием, Калмана Калотая, такие ТНК должны соответствовать следующим критериям [2]:

- быть отдельными юридическими лицами;

- должны быть учреждены государством для реализации коммерческой деятельности;

- должны проводить операции по прямым иностранным инвестициям (ПИИ), имея за рубежом филиалы или будучи вовлечены в международное производство без приобретения активов;

- должны быть контролированы правительством или правительственным субъектом, таким как Центральный Банк, государственное агентство, национальный инвестиционный фонд (но не пенсионный фонд), с долей больше $10 \%$ владения, либо государственный субъект должен быть крупнейшим держателем акций или владельцем «золотых акций» [2].

Таким образом, ТНК с государственным участием находятся на пересечении двух крупных категорий: ТНК (в основном частные фирмы) и государственных компаний (в основном один владелец- государство).

Далее рассмотрим географическое и секторальное распределение ТНК с государственным участием (Рис.1). Больше половины ТНК с госу- дарственным участием имеют головной офис в развивающихся странах (57\%), в развитых странах - около 40\%. Большинство ТНК с государственным участием из развитых стран расположено в ЕС, почти одна треть из них. Основными странами происхождения из развивающихся являются Китай (18\%), Малайзия (5\%), Индия (4\%), Южная Африка (4\%) и Россия (3\%) [6].

Географическое распределение иностранных филиалов государственных ТНК отражает их корпоративные стратегии, ориентированные на крупнейшие потребительские рынки для своих услуг (особенно финансы, коммунальные услуги и транспорт). Однако следует указать, что предпочтения европейских и азиатских ТНК с госучастием отличаются. Европейские ТНК более регионализированы, потому что склонны располагать свои иностранные филиалы по соседству, в страны ЕС, а также в США. Азиатские компании в этом смысле более глобализированы, так как предпочитают разные направления для своих филиалов, а именно страны ЕС, США и некоторые азиатские страны, как например Сингапур. В 2017 г. больше всего филиалов ТНК с государственным участием были расположены в ЕС (33200), далее в США (8706), в Австралии (3726), в Китае (3630), в Гонконге (3521) [6].

Из Таблицы 1 следует что, крупнейшие ТНК с государственным участием принадлежат развитым странам, в частности странам-членам ЕС, что свидетельствует о большой централизации государственной власти.

В числе крупнейших ТНК мира вошли также

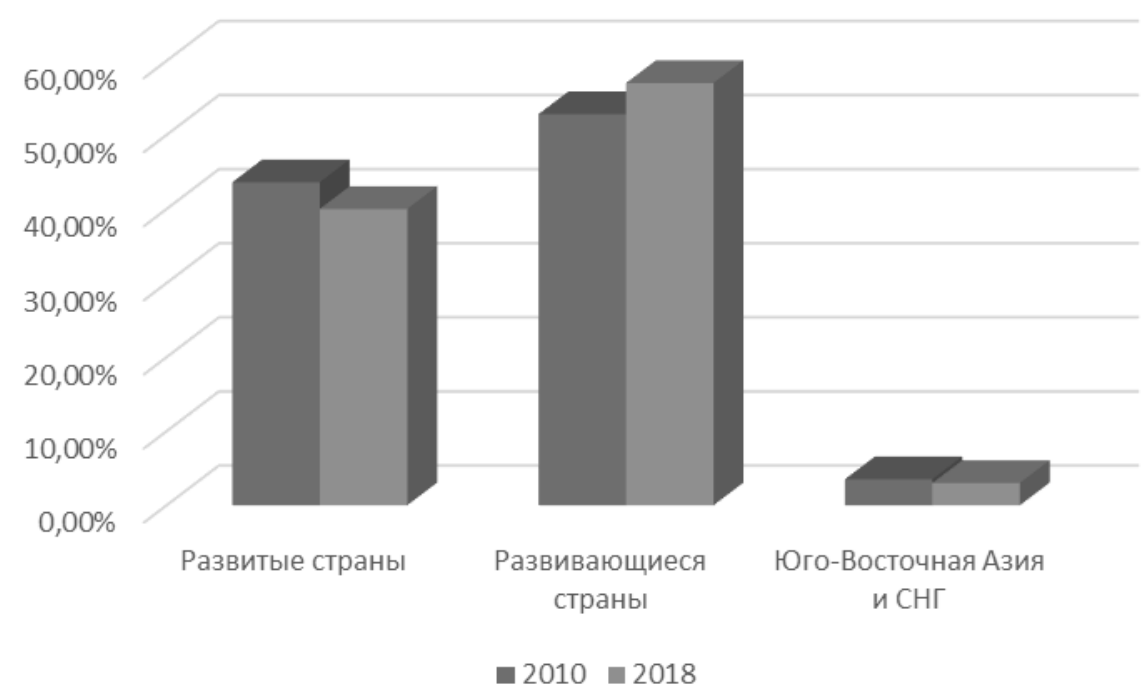

Puc. 1. Географическое происхождение ТНК с государственным участием Источник: составлено автором по данным WIR2011, 2017, 2019 
Таблица 1. Крупнейшие ТнК с государственным участием в 2019 году, вошедшие в топ-100 крупнейших ТНК мира

\begin{tabular}{|c|c|c|c|c|}
\hline $\begin{array}{l}\text { Место в рей- } \\
\text { тинге } 2019 \text { г. }\end{array}$ & $\begin{array}{l}\text { Место в рей- } \\
\text { тинге } 2017 \text { г. }\end{array}$ & Компания & Страна происхождения & Отрасль \\
\hline 6 & 6 & Volkswagen Group & Германия & Автомобилестроение \\
\hline 18 & 18 & Enel SpA & Италия & $\begin{array}{l}\text { Электроэнергия, газо- и } \\
\text { водоснабжение }\end{array}$ \\
\hline 28 & 27 & Deutsche Telekom AG & Германия & Телекоммуникации \\
\hline 30 & 33 & EDF SA & Франция & $\begin{array}{l}\text { Электроэнергия, газо- и } \\
\text { водоснабжение }\end{array}$ \\
\hline 32 & 23 & Eni SpA & Италия & Нефтепереработка \\
\hline 40 & 81 & $\begin{array}{l}\text { China COSCO Shipping } \\
\text { Corp Ltd }\end{array}$ & Китай & $\begin{array}{l}\text { Грузоперевозки и скла- } \\
\text { дирование }\end{array}$ \\
\hline 42 & 54 & $\begin{array}{l}\text { Nippon Telegraph \& } \\
\text { Telephone Cor }\end{array}$ & Япония & Телекоммуникации \\
\hline 50 & 46 & Airbus SE & Франция & Авиастроение \\
\hline 51 & 37 & Engie & Франция & $\begin{array}{l}\text { Электроэнергия, газо- и } \\
\text { водоснабжение }\end{array}$ \\
\hline 52 & 52 & Orange SA & Франция & Телекоммуникации \\
\hline 56 & 44 & $\begin{array}{l}\text { China National Offshore } \\
\text { Oil Corp (CNOOC }\end{array}$ & Китай & $\begin{array}{l}\text { Добыча полезных иско- } \\
\text { паемых и нефти }\end{array}$ \\
\hline 59 & 55 & Equinor ASA & Норвегия & Нефтепереработка \\
\hline 62 & - & State Grid Corp of China & Китай & $\begin{array}{l}\text { Электроэнергия, газо- и } \\
\text { водоснабжение }\end{array}$ \\
\hline 67 & - & $\begin{array}{l}\text { China National Chemical } \\
\text { Corp (ChemChina) }\end{array}$ & Китай & $\begin{array}{l}\text { Химическая промыш- } \\
\text { ленность }\end{array}$ \\
\hline 69 & 68 & Renault SA & Франция & Автомобилестроение \\
\hline 97 & - & $\begin{array}{l}\text { China Minmetals Corp } \\
\text { (CMC) }\end{array}$ & Китай & Металлургия \\
\hline
\end{tabular}

Источник: World Investment report 2019: special economic zones /UNCTAD, UN, New York, Geneva.

URL: https://unctad.org/en/PublicationsLibrary/wir2019_en.pdf, стр.25.

ТНК с государственным участием из развивающихся стран, а именно из Китая, и их всего лишь 5! Этот факт доказывает, что роль ТНК с государственным участием часто недооценивается, потому что такие ТНК намного крупнее частных, а их доля в сотне крупнейших ТНК мира составляет 15\% [7]. Так, немецкая компания Volkswagen Group является крупнейшей нефинансовой ТНК с госучастием в мире, далее следует немецкая Deutsche Telekom AG, французская EDF SA и итальянская компания Eni Sp A.

ТНК с государственным участием чаще всего встречаются в сфере финансовых услуг и в добыче полезных ископаемых. Основные отрасли, охватываемые ими это финансы, страхование, коммунальные услуги (особенно электричество), транспорт и горнодобывающая промышленность. Таким образом, около $70 \%$ ТНК с государственным участием заняты в секторе услуг, в промышленности - 23\%, а в первичном секторе$7 \%[6]$.

Наверное, самый интересный аспект данной темы является степень участия государства в THK с госучастием, а также его интересы в создании таких компаний. В большинстве случаев доля государства в таких компаниях либо мажоритарное, либо стопроцентное, что дает ему возможность влиять на принятие решений и в создании стратегии данной ТНК. Полный контроль (100\%-ое владение) является наиболее предпочтительным типом. По данным ЮНКТАД, среди ТНК, для которых были получены точные данные, более трети полностью принадлежат их правительствам, а еще $29 \%$ контролировались через мажоритарную собственность [6]. В 16\% случаев государство имеет миноритарную долю менее 25\% акций [6]. В таких случаях государство по-прежнему представляется в совете директоров, но его участие в управлении предприятием обычно более избирательно, сосредоточив внимание на ключевых стратегических решениях.

В результате исследований, было выявлены три основные позиции государства, когда речь идет о зарубежной экспансии ТНК с госу- 
дарственным участием: государство активно поддерживает, строго против или же остается нейтральным, безразличным к таким процессам. В первом случае, когда государство активно поддерживает зарубежную экспансию национальных ТНК, появляется много ТНК с государственным участием, например, такую политику можно встретить в Китае, где она называется «Go Global».

Во втором случае, когда правительство является препятствием интернационализации ТНК, власти объясняют свою позицию негативными последствиями для внутреннего рынка, как например, в Италии, где государство неоднократно высказывало озабоченность по поводу потенциального воздействия интернационализации итальянских ТНК на уровень безработицы в стране.

Третий случай, это когда правительство равнодушно относится к интернационализации ТНК с госучастием, как, например, в отношении ПИИ компании Vattenfall (Швеция) в Африке. Таким образом, можно сделать вывод о том, что в развитых странах государство не охотно решается на зарубежную экспансию ТНК с государственным участием, проявляя интерес больше к внутреннему рынку, а в развивающихся странах наоборот, правительство старается поддержать свои ТНК в зарубежных ПИИ.

На Рис. 2 представлены основные отрасли трансграничных приобретений ТНК с госу- дарственным участием. За весь период 20102018 гг., слияния и поглощения этого вида ТНК не превышали 2\% от всех сделок, однако они характеризовались огромными масштабами [7]:

- слияние в 2002 г. шведской Telia AB с финской Sonera Corp, обе ТНК с государственным участием с мажоритарным владением, привело к созданию телекоммуникационной корпорации стоимостью 6,3 млрд. долл. США;

- приобретение в 2013 г. российским нефтяным гигантом Роснефть компании TNK-BP Ltd за 55 млрд. долл. США;

- поглощение в 2017 г. швейцарской Syngenta китайским химическим концерном ChemChina за 42 млрд. долл. США.

Чаще всего государства создают свои ТНК или приобретают значительную долю в национальной ТНК преследуя долгосрочные стратегические цели всей страны: для реализации приоритетных целей развития, для преодоления провалов внутреннего рынка, для владения монополиями в сфере стратегических ресурсов $[1,3]$. Также государство заинтересовано в деятельности ТНК с государственным участием с точки зрения национальной безопасности, конкуренции, управления природными ресурсами, для соблюдения социальных и экологических стандартов, а также чтобы оказать влияние на развитие принимающей страны и на ее торговую политику.

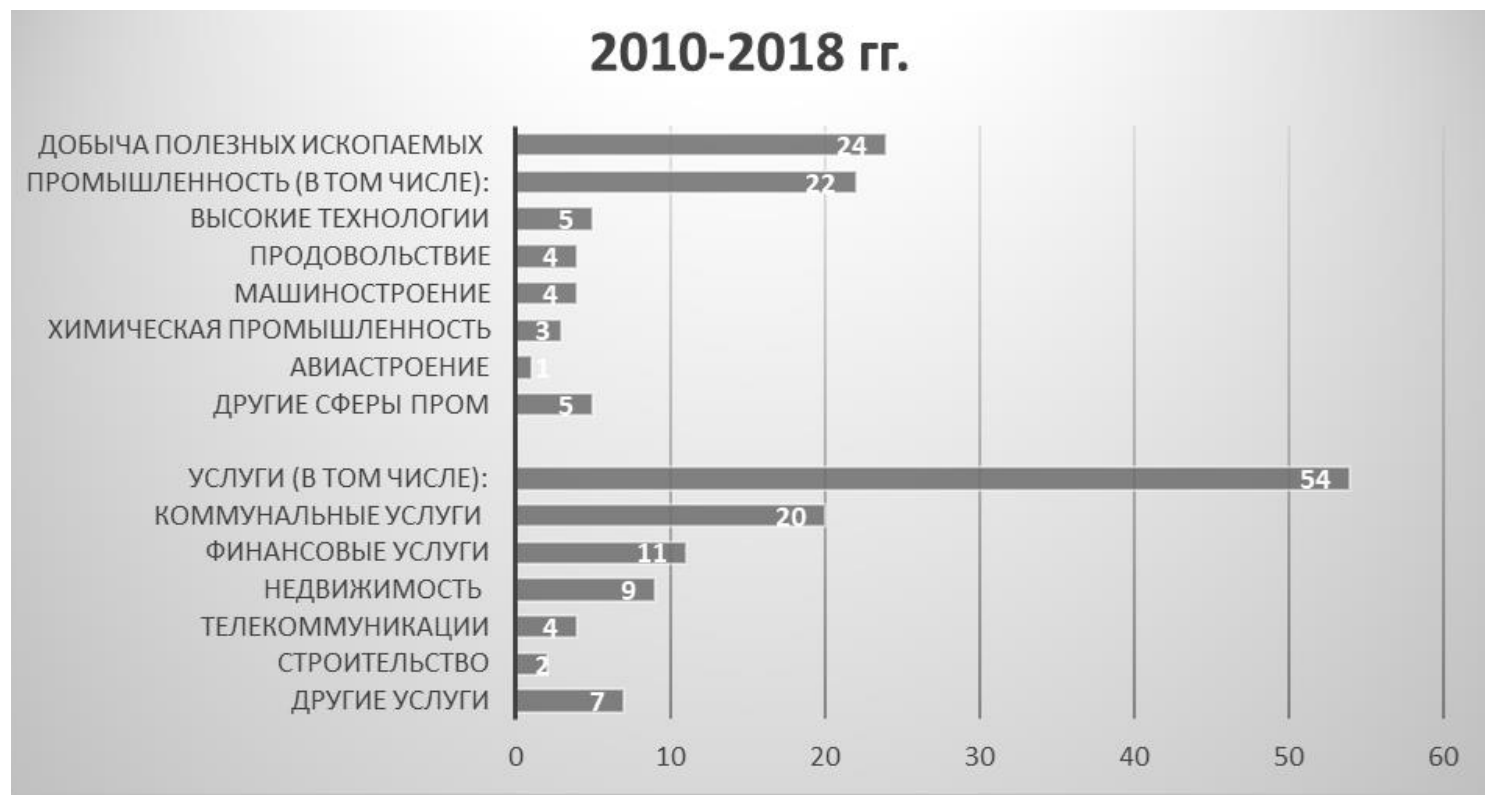

Puc. 2. Трансграничные приобретения ТНК с государственным участием за 2010-2018 гг. по секторам, в\% от всех сделок Источник: составлено автором по данным WIR2019. 


\section{Выводы:}

- ТНК с государственным участием являются новым объектом для экономистов, поэтому еще не до конца разработана методология изучения, она постоянно совершенствуется;

- ТНК с государственным участием в основном базируются в развивающихся странах (57\%), однако крупнейшие принадлежат развитым странам из ЕС, что также является интересным явлением. Получается, что по количеству больше всего таких ТНК из развивающихся стран, а по размерам и значимости компаний лидируют развитые страны.

- ТНК создаются в ключевых для экономики отраслях (энергетика, телекоммуникации, добыча полезных ископаемых). Видимо, государство не может позволить, чтобы в ключевых отраслях проникали иностранные компании, которые представляют интересы других государств, что может сказаться на собственной государственной безопасности.

\section{Библиографический список}

1. Governments as owners: state-owned multinational companies. Alvaro Cuervo-Cazurra, Andrew Inkpen, Aldo Musacchio, Kannan Ramaswamy. URL: https://ash.harvard.edu/bitstream/handle/1/15787971/chervo-cazurra\% 2cinkpen\%2cmusacchio\%2cramaswamy_governments-as-owners-SOMNCs.pdf?sequence=3\&isAllowed=y, 29 c.

2. State-owned multinationals: an emerging market phenomenon? Kalman Kalotay. 9 December 2017, Kyoto, Japan. (Доступ с сайта Researchgate.net)

3. State-owned enterprises as Multinationals: Theory and Research Directions. Aldo Musacchio, Sergio G. Lazzarini/ October, 2018. (Доступ с сайта Researchgate.net)

4. State ownership reinvented? Explaining performance differences between State-Owned and Private Firms. Aldo Musacchio, Sergio G. Lazzarini/ April 2018. (Доступ с сайта Researchgate.net)

5. World investment report 2011: Non-equity modes of international production and development/UNCTAD, UN, New York, Geneva. URL: http://unctad.org/en/publicationslibrary/wir2011_en.pdf, 251 c.

6. World Investment report 2017: investment and the digital economy/UNCTAD, UN, New York, Geneva. URL: http:// unctad.org/en/PublicationsLibrary/wir2017_en.pdf, 252 c.

7. World Investment report 2019: special economic zones /UNCTAD, UN, New York, Geneva. URL: https://unctad.org/ en/PublicationsLibrary/wir2019_en.pdf, 222 c. 